\title{
Olhares para o fim do mundo
}

\section{Looks to the end of the world}

\section{Lucas Jacobina}

Universidade Federal do Mato Grosso do Sul. Faculdade de Artes, Letras e

Comunicação

\begin{abstract}
Este ensaio foi realizado como trabalho
\end{abstract} final para disciplina de Fotografia Documental, ministrada por Rodrigo Sombra, na UFMS, em maio de 2020, quando as aulas já não eram mais presenciais. De temática livre, escolhi representar no ensaio o encontro entre o meu eu interior e o caos psicológico na pandemia. Por vezes, esta série fotográfica também pertencia a uma dor coletiva do momento em que estávamos vivendo.

Como estudante de cinema, não posso negar que me debrucei na cinematografia de dois diretores os quais influenciaram a perspectiva de meu trabalho. Por vezes, eu me encontrava nos filmes de Ingmar Bergman como um de seus personagens em Luz de Inverno (1963) e Persona (1967), como se a aflição do mundo me consumisse à medida que "Deus está em silêncio" e que a linha tênue da vida e da morte já não existisse mais. Noutros momentos, era como se eu estivesse em O Deserto Vermelho (1964), de Michelangelo Antonioni, onde a incomunicabilidade, a solidão e o medo assolam aquilo que é mais profano no homem.

Numa investigação do sofrimento do indivíduo na pandemia, surge em meu ensaio fotográfico uma senhora carregando uma flor. Essa mesma flor está no poema Áporo, de Carlos Drummond de Andrade, outra inspiração que me acompanhou durante a criação destas imagens. Em Drummond, "uma orquídea forma-se" numa paisagem desoladora, um "país bloqueado" que nos sufoca e nos oprime. É a metáfora da esperança em meio ao caos.

Portanto, conforme os filmes e a poesia de Drummond me proporcionavam uma compreensão do indivíduo na pandemia, consegui através de meu ensaio fotográfico confrontar a minha própria angústia. Afinal, compreendi que o fazer artístico resiste a um mundo nefasto, onde pouco se crê na poetização da vida. 


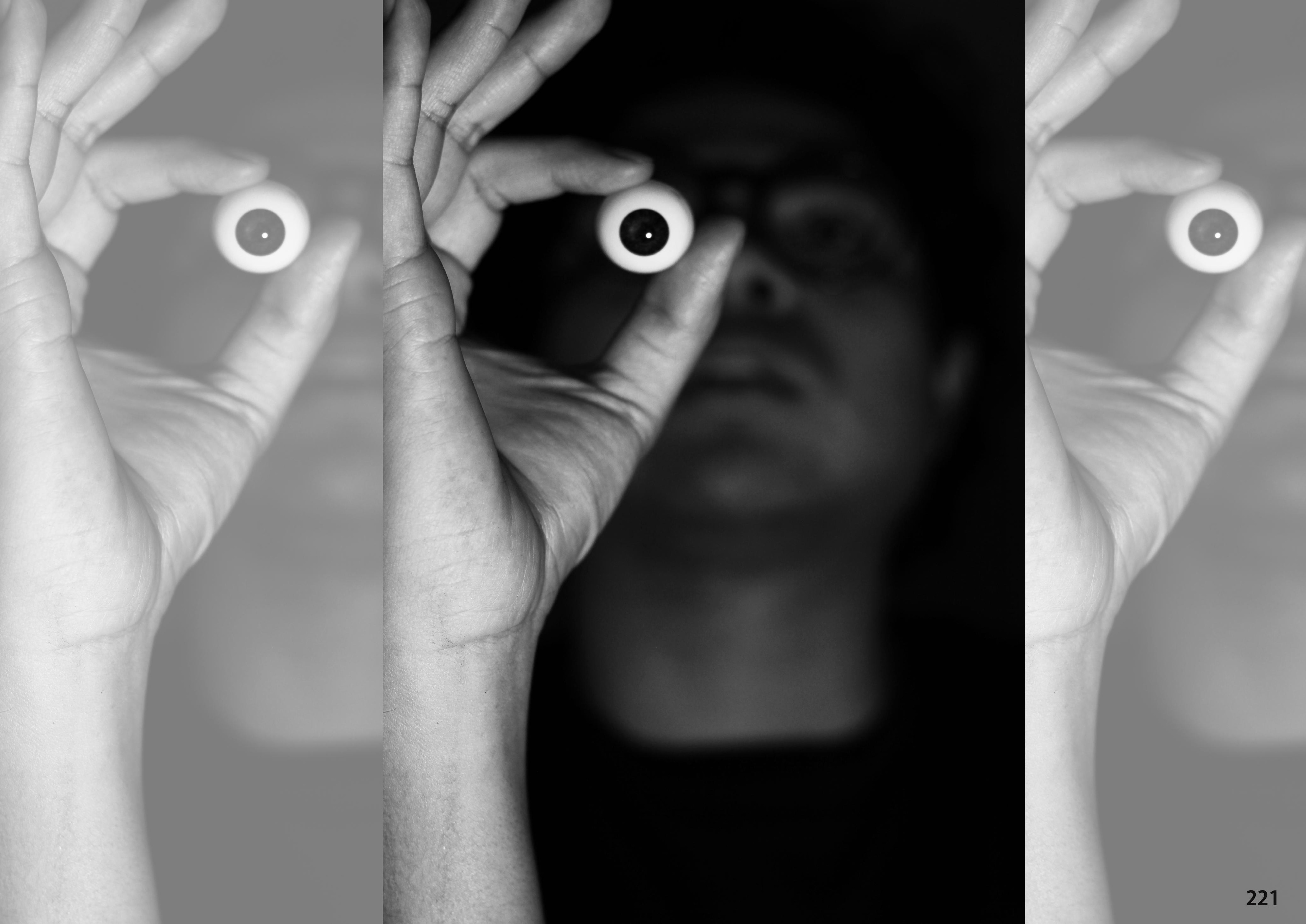




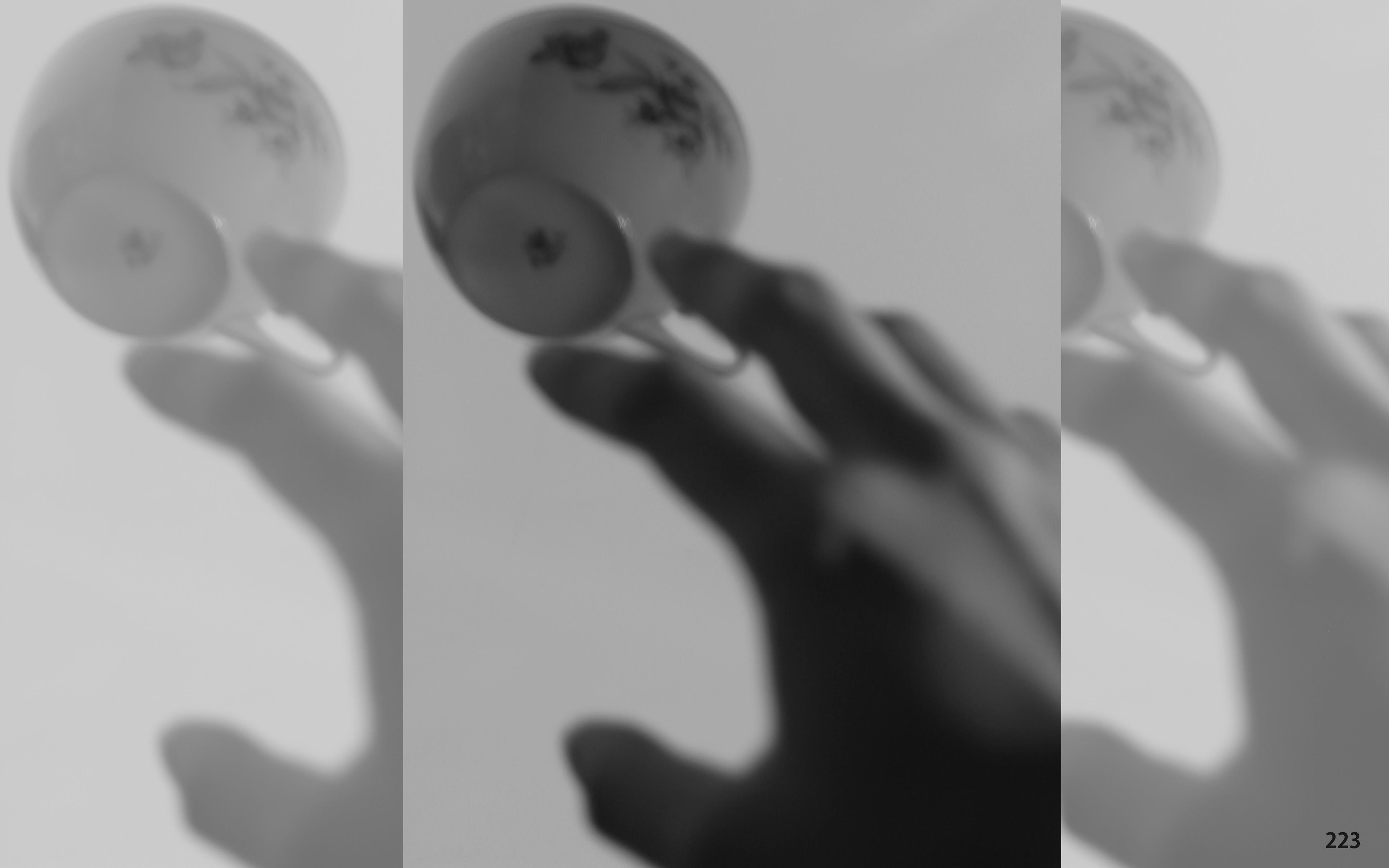




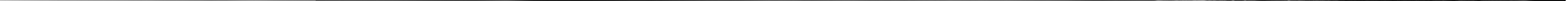




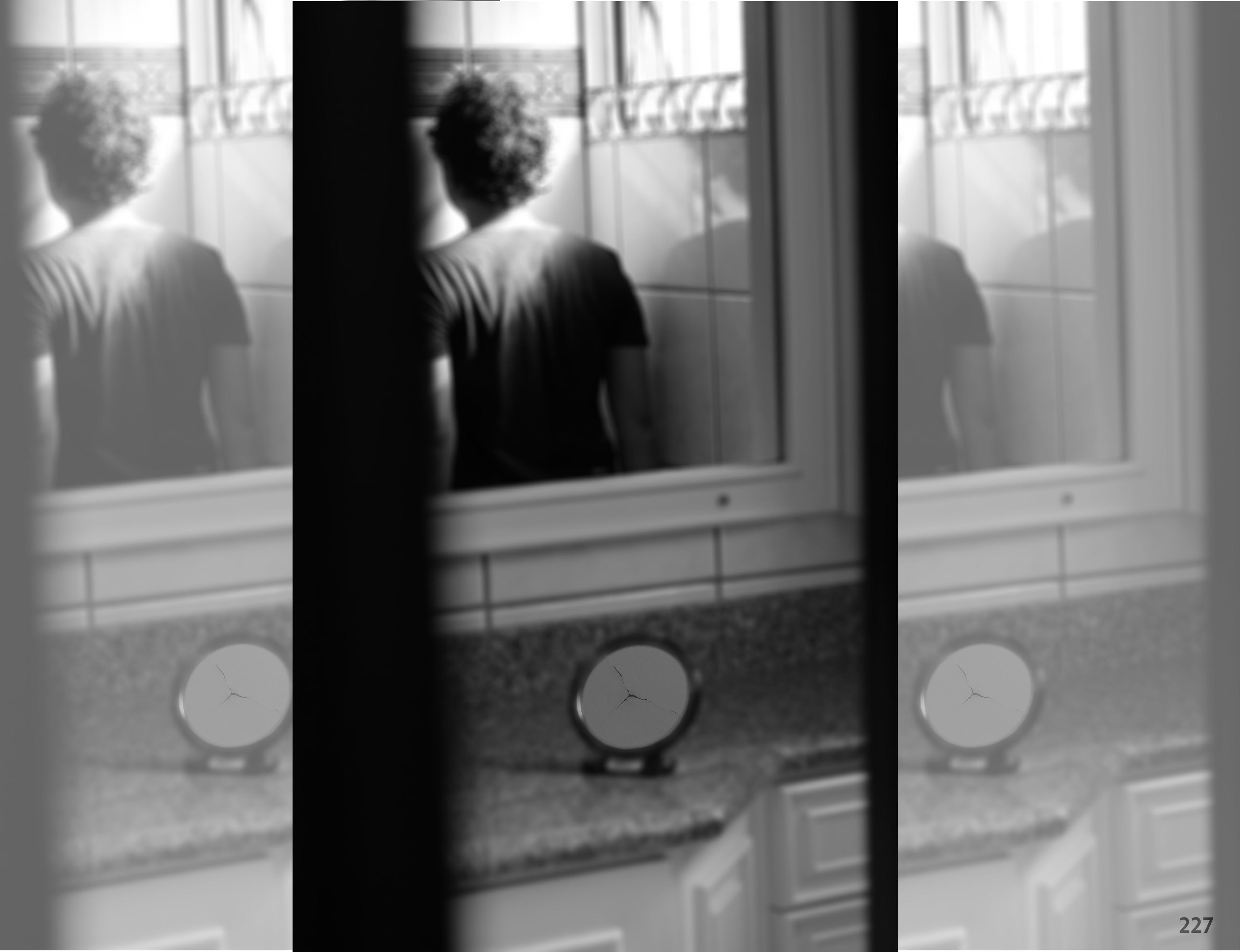




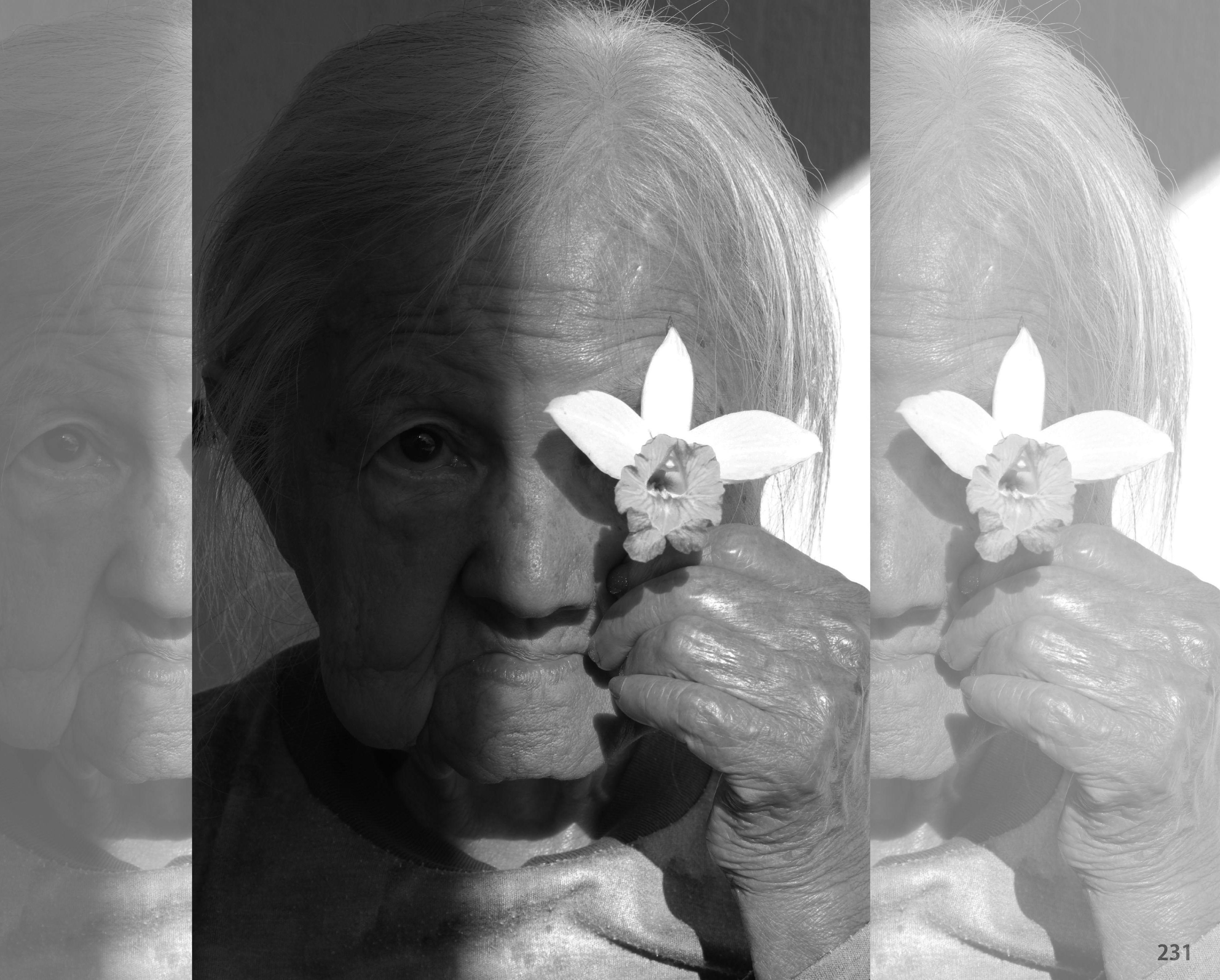

